\title{
Incidentally detected bilaterally symmetrical seminal and vas calcification in young infertile male: a case report, literature review and algorithm for diagnosis
}

\author{
Rahul Yadav, MBBS, MS (Surg); Apul Goel, MCh, DNB (Urol); Satya N. Sankhwar, MS (Surg), MCh (Urol); \\ Neeraj Kumar Goyal, MBBS, MS
}

Department of Urology, Chattrapati Shahuji Maharaj Medical University (King George's Medical College), Lucknow, Uttar Pradesh, India

Cite as: Can Urol Assoc J 2012;6(5):E206-E208. http://dx.doi.org/10.5489/cuaj.12009

\section{Abstract}

Bilateral seminal and vas calcification is not common, especially in young age. Association with many disease conditions has been described, with diabetes mellitus being the most common association. A 34-year-old man presented with primary infertility and right upper ureteric calculus. His evaluation revealed extensive, bilateral seminal and vas calcification with normal semen analysis and firsttime detected diabetes mellitus. His female partner was evaluated and found to have bilateral fallopian tubes blockage. We reviewed the literature and present here the algorithm for diagnosis of such patients, along with details of this particular patient.

\section{Case report}

A 34-year-man presented with primary infertility (married 4 years ago) and dull aching right flank pain for 6 months. An $x$-ray of his abdomen showed right upper ureteral stone with calcified tubular structures in the pelvis, suggestive of vas calcification and pelvic vessel calcification (Fig. 1). Serum parameters showed raised blood sugars (fasting blood sugar $14.83 \mathrm{mmol} / \mathrm{L}$, postprandial blood sugar $25 \mathrm{mmol} / \mathrm{L}$ and glycosylated hemoglobin $9.4 \%$ ) with normal renal functions, although there was no history or complications of diabetes mellitus (DM). Plain CT abdomen revealed bilateral and symmetric calcifications of the seminal vesicles and vas deferens (Fig. 2) in their intra-pelvic course with right upper ureteral calculus. Semen examination was normal, including sperm count and fructose level.

The patient underwent extracorporeal shock wave lithotripsy for the ureteral calculus and achieved stone-free status. Euglycemic status was achieved after dietary management and starting oral hypoglycemic drugs. His female partner had bilateral complete fallopian tubes blockage.

\section{Discussion}

Calcification of vas deferens is relatively specific to DM and was initially noted by Marks and Ham in 1942, who found that 7 of their 9 cases with vas calcification were diabetics. ${ }^{1,2}$ Culver and Tennenhaus reported that $70 \%$ of males who had vas calcification also had diabetes. ${ }^{3}$ There are other etiologies associated with the calcification of the seminal and vas deferentia (Table 1). ${ }^{4-8}$ Non-inflammatory degenerative vas deferens calcification as seen in diabetics can also be seen as a manifestation of aging. ${ }^{9}$ Occasionally, in diabetics, the calcification continues into the inguinal canal and may also be associated with infertility. Pathologically, diabetic vas deferens calcification can be differentiated from the chronic inflammatory type. ${ }^{9}$ Chronic inflammatory calcification is usually intraluminal which may be unilateral and segmental, while the calcification seen in diabetes is usually mural and symmetrical. On the other hand, vascular calcifications follow the course of the pudendal and spermatic arteries and are denser and thicker. ${ }^{9}$

The reason for predilection for vas calcification in diabetes is unclear. Vas calcification is a chronic process and usually develops over a period of years. ${ }^{10}$ In a series of 56 men with vas calcification, the mean duration of diabetes was 18.3 years. ${ }^{10}$ Our patient was not aware of his glycemic status before presentation and was found to have diabetes during evaluation. One possible explanation for this complication could be that diabetic patients are hyperglycemic for up to 6 years before being diagnosed. ${ }^{11}$ This patient was unusually young at the time of presentation as the usual age of calcification described in the literature is between fifth and sixth decades of life. ${ }^{10}$ There was also calcification of the pelvic vessels and this is common in these patients. ${ }^{10}$

DM is a risk factor for infertility and different pathophysiological mechanisms have been described. ${ }^{12,13}$ However, whether vas calcification is an independent risk factor is poorly documented. This patient had normal semen analysis (3 reports), while his partner had tubal block. Although, his 


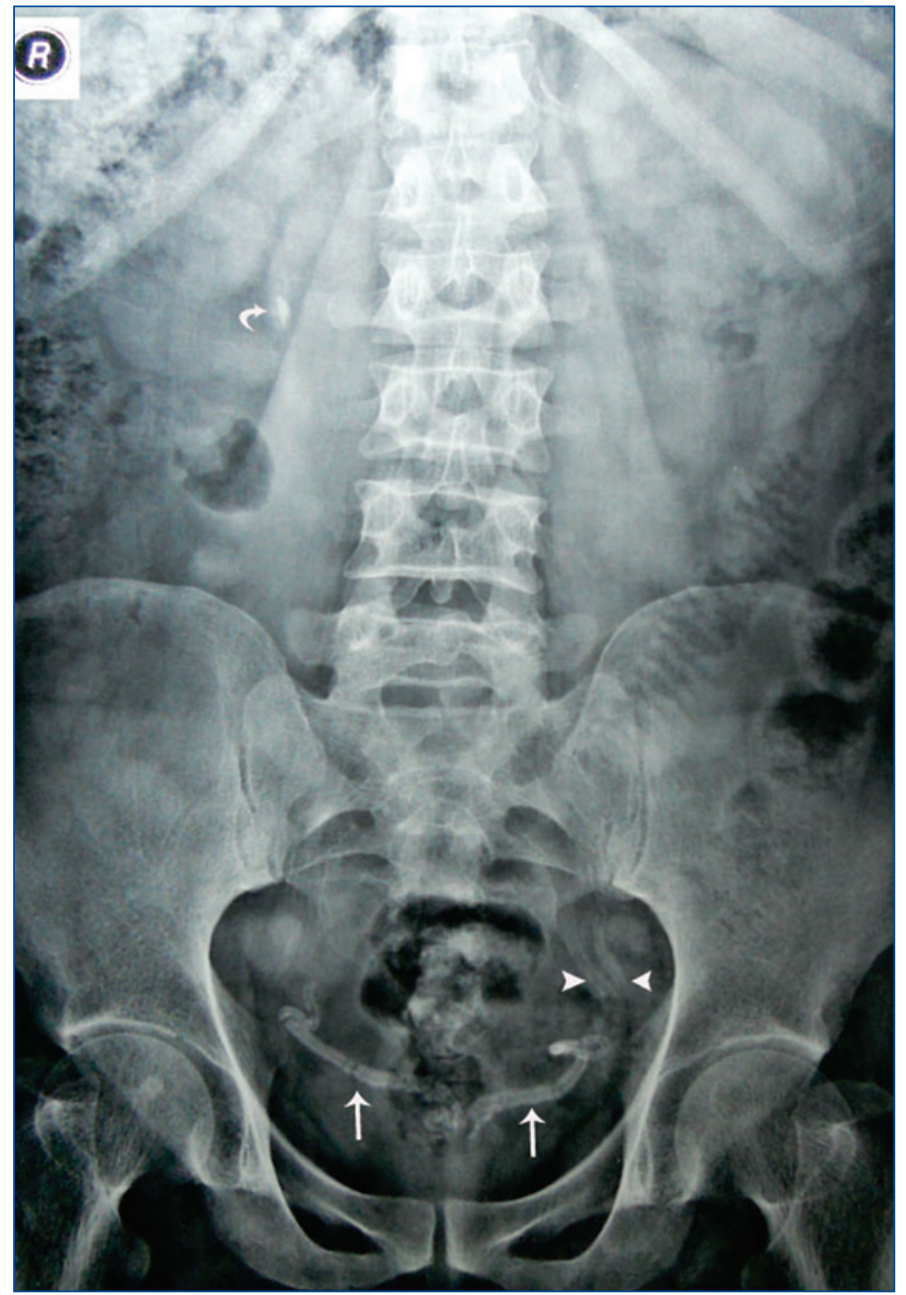

Fig. 1. Plain $x$-ray kidney, ureter and bladder (KUB) region showing right upper ureteral calculus (curved arrow) and bilateral vas calcification (straight arrow) with calcification in pelvic vessels (arrow head).

exact fertility status could not be ascertained, we presumed that it was normal due to his normal semen parameters. Seminal and vas calcification highlights the need to investigate further to find out correctable causes of calcification in these groups of patients. A simple algorithm to expedite good clinical management is useful (Fig. 3). The initial evaluation includes thorough history and physical examination to search for an associated disease condition (like diabetes, tuberculosis, uremia). Further evaluation of urine and blood will elucidate the cause (e.g., blood glucose for diabetes, serum creatinine for uremia, prostate-specific antigen for carcinoma and parasitic ova in urine for schistosomiasis). Invasive investigations, like transrectal ultrasound, will reveal potential area of obstruction, prostatitis or hypoechoic areas in cases of prostate cancer. We investigated our patient using the algorithm (Fig. 3); we found that he had DM and, to our surprise, the female partner had bilateral tubal blocks causing infertility.

\section{Table 1. Associated aetiologies with calcification of the seminal vesicles and vasa deferentia}

Primary

\begin{tabular}{ccc}
\hline Secondary & Idiopathic & \\
\hline Metabolic & $\begin{array}{c}\text { Diabetes mellitus (strongest } \\
\text { association) } \\
\text { Uremia causing secondary } \\
\text { hyperparathyroidism } \\
\text { Chronic inflammation }\end{array}$ & Tuberculosis \\
& Schistosomiasis \\
& Gonorrhoea \\
& Chlamydia \\
& Prostatitis \\
& Other \\
Mechanical & Intraluminal calculi \\
obstruction & Congenital abnormalities \\
& Fibrosis \\
& \\
Invasive carcinoma & \\
Gonadal dysgenesis & \\
syndromes & \\
\hline
\end{tabular}

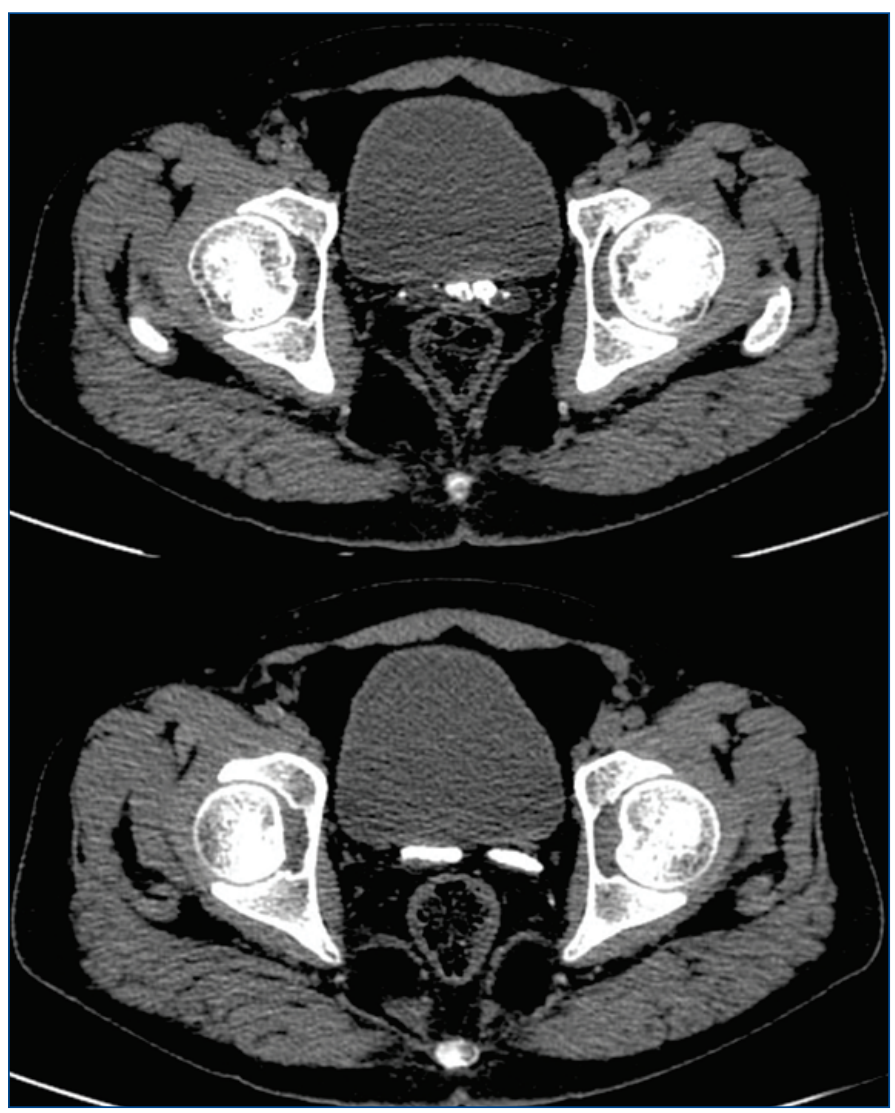

Fig. 2. Non-contrast computed tomography scan showing calcification of seminal vesicles and vas deferens. 
Yadav et al.

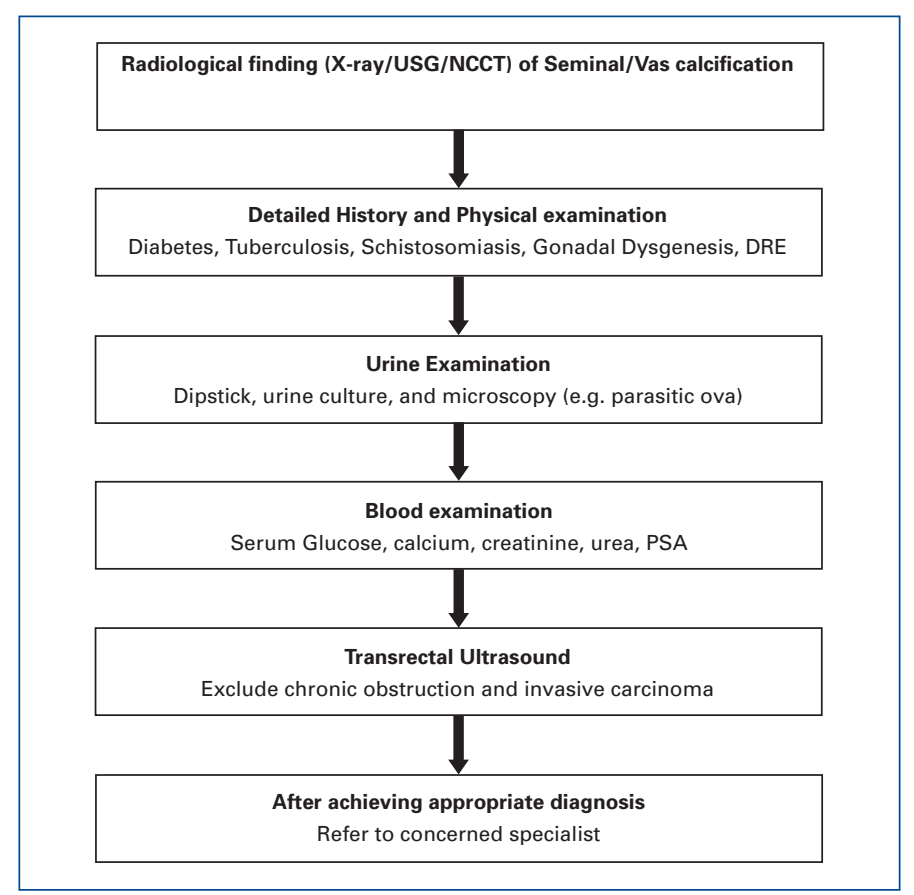

Fig. 3. Diagnostic algorithm for management of seminal and vas calcification.

\section{Conclusion}

This report describes bilateral seminal and vas calcification, which is not common in young males. We used a diagnostic algorithm to manage our patient and this can be used for other such patients.

Competing interests: None declared.

This paper has been peer-reviewed.

\section{References}

1. Marks JH, Ham DP. Calcicication of vas Deferens. AJR Am J Roentgenol 1942;47:859.

2. Wilson JL, Marks JH. Calcification of the vas deferens; its relation to diabetes mellitus and arteriosclerosis. N Engl J Med 1951;245:321-5. http://dx.doi.org/10.1056/NEJM195108302450902

3. Culver GJ, Tannenhaus J. Calcification of the vas deferens in diabetes. J Am Med Assoc 1960; 173:648-51. hitp://dx.doi.org/10.1001/jama.1960.03020240036006

4. González Ortega FJ, Duque Fernández de Vega S, Garrido Pareja F. Bilateral calcification of seminal vesicles and vas deferens. Actas Urol Esp 2009;33:216.

5. Patel $H R$, Arya $M, O^{\prime} D o n o g h u e ~ E P$. Calcified seminal vesicles and vasa deferentia: "beware or be aware". Scand I Urol Nephrol 2001;35:79-80.

6. Vilana R, Corachan M, Gascon J, Valls E, Bru C. Schistosomiasis of the male genital tract: transrectal sonographic findings. J Urol 1997; 158:1491-3. http://dx.doi.org/10.1016/S0022-5347(01)64251-4

7. Kuligowska E, Fenlon HM. Transrectal US in male infertility: spectrum of findings and role in patient care. Radiology 1998;207:173-81.

8. Griffths $G J$, Clements R, Jones DR, et al. The ultrasound appearances of prostate cancer with histological correlation. Clin Radiol 1987;38:219-27. http://dx.doi.org/10.1016/S0009-9260(87)80048-X

9. Rodriguez-de-Velasquez A, Yoder IC, Velasquez PA, et al. Imaging the effects of diabetes on the genitourinary system. Radiographics 1995;15:1051-68.

10. No authors listed. Calcification of the Vas Deferens and Diabetes. Can Med Assoc J 1960;83:659.

11. Robertson C. Diabetes update.The untold story of disease progression. RN 2001;64:60-4.

12. Agbaje $I M$, Rogers $D A$, McVicar $C M$, et al. Insulin dependent diabetes mellitus: implications for male reproductive function. Hum Reprod 2007;22:1871-7. http://dx.doi.org/10.1093/humrep/dem077

13. Amaral S, Moreno AJ, Santos MS, et al. Effects of hyperglycemia on sperm and testicular cells of GotoKakizaki and streptozotocin-treated rat models for diabetes. Theriogenology 2006;66:2056-67. http:// dx.doi.org/10.1016/i.theriogenology.2006.06.006

Correspondence: Professor Apul Goel, Department of Urology, CSM Medical University (King George's Medical College), Lucknow-226003, Uttar Pradesh, India; fax: +91-522-2256543; goelapul1@rediffmail.com 